\title{
Coronary heart disease patient with implantable cardioverter desfibrilator and electrical storm submitted to ventricular tachycardia ablation
}

Paciente coronariopata com cardiodesfibrilador e tempestade elétrica submetido à ablação de taquicardia ventricular

Nilton José Carneiro da Silva ${ }^{1}$, Bruno Pereira Valdigem ${ }^{1}$, Christian Luize ${ }^{2}$, Fernando Lopes Nogueira ${ }^{2}$, Claudio Cirenza ${ }^{3}$, Guilherme Fenelon ${ }^{3}$, Marcia Regina Pinho Makdisse ${ }^{1}$, Fátima Dumas Cintra ${ }^{3}$, Angelo Amato Vincenzo De Paola ${ }^{3}$

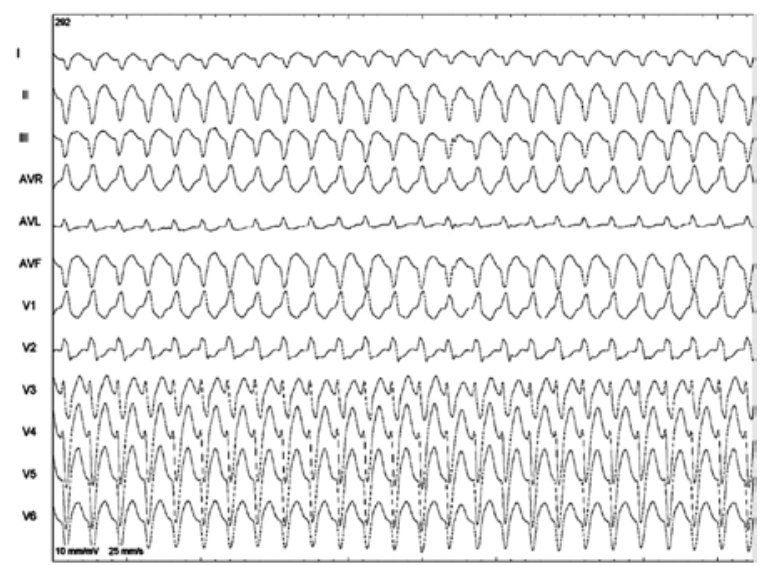

Figure 1. Electrocardiogram presenting clinical tachycardia at an Emergency Department Unit
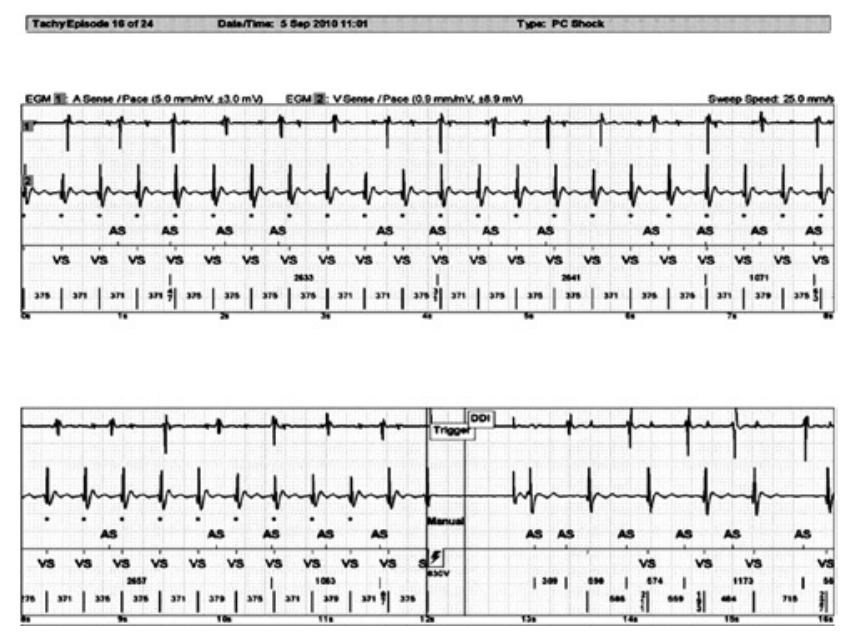

Figure 2. Implantable cardioverter defibrillator (ICD) record of ventricular tachycardia and cardioversion

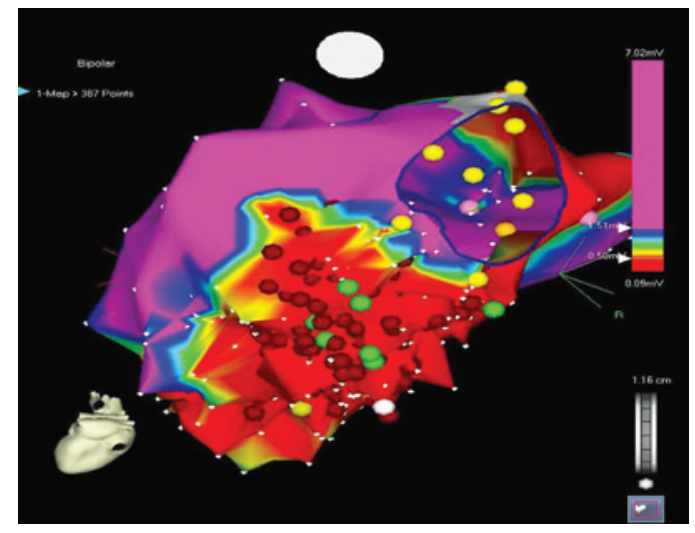

Figure 3. Electroanatomical map in posterior projection, mitral ring identified at 1 o'clock, red area corresponding to low voltage - "scar" and red circles are the sites where radiofrequency was applied

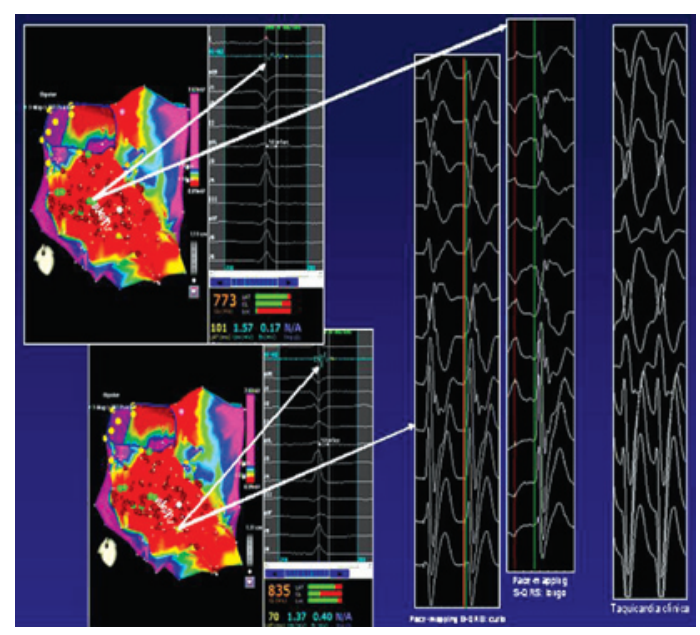

Figure 4. Correlation of points with intracavitary electrograms and surface electrocardiogram, guiding ventricular tachycardia ablation 
A 69-year old diabetic patient with $\mathrm{O}_{2}$-dependent chronic obstructive pulmonary disease (COPD), history of myocardial revascularization in 1998 and one episode of ventricular tachycardia and placement of cardiac defibrillator in 2003. He was seen at the Emergency Department in February 2010 with palpitations and four shocks in the last two hours. The electrocardiogram showed wide QRS tachycardia with right bundle branch block (RBB) and superior axis (Figure 1). Arrhythmia reverted after sedation and eletrical cardioversion (ECV). The implantable cardioverter defibrillator (ICD) evaluation demonstrated appropriate therapy (shock for ventricular tachycardia), confirming the main hypothesis (Figure 2). He presented recurrence of tachycardia despite the optimized drug treatment, including intravenous amiodarone. The use of the antitachycardia pacing (ATP) (fast stimuli) through the ICD did not stop tachycardia; on the contrary, it would even increase it. Hence the patient was submitted to catheter ablation of ventricular tachycardia. Since there was more than one inducible tachycardia episode, and the patient did not tolerate arrhythmia for a prolonged period, it was decided to perform combined ablation of the arrhythmic substrate, guided by the electroanatomical map (CARTO) (Figure 3) to assist with electrophysiological data (Figure 4). The procedure was successful and there have been no new ventricular tachycardia episodes in clinical follow-up.

The use of the electroanatomical map in electrophysiological procedures enabled managing complex arrhythmias in patients at high pre-procedure risk ${ }^{(1)}$. Atrial fibrillation and ventricular tachycardia related to structural cardiopathy have been addressed with this technology in most specialized centers, showing superior results than the conventional technique ${ }^{(2-3)}$.

\section{REFERENCES}

1. Aliot EM, Stevenson WG, Almendral-Garrote JM. EHRA/HRS Expert Consensus on Catheter Ablation of Ventricular Arrhythmias: developed in a partnership with the European Heart Rhythm Association (EHRA), a Registered Branch of the European Society of Cardiology (ESC), and the Heart Rhythm Society (HRS); in collaboration with the American College of Cardiology (ACC) and the American Heart Association (AHA). Heart Rhythm. 2009;6(6):886-933.

2. Hsia HH, Lin D, Sauer WH, Callans DJ, Marchlinski FE. Anatomic characterization of endocardial substrate for hemodynamically stable reentrant ventricular tachycardia: identification of endocardial conducting channels. Heart Rhythm. 2006;3(5):503-12.

3. Soejima K, Suzuki M, Maisel WH, Brunckhorst CB, Delacretaz E, Blier L, et al. Catheter ablation in patients with multiple and unstable ventricular tachycardias after myocardial infarction: short ablation lines guided by reentry circuit isthmuses and sinus rhythm mapping. Circulation. 2001;104(6):664-9. 